\title{
AMÉRICA LATINA EN LAS REVISTAS EUROPEAS DE ANTROPOLOGÍA, DESDE LOS INICIOS HASTA 1880. DE LA PRESENCIA TEMÁTICA A LA PARTICIPACIÓN ACADÉMICA
}

POR

\author{
MÓNICA QUIJADA
}

Instituto de Historia, CSIC 1

En la segunda mitad del siglo XIX se consolidó la institucionalización de la Antropología como ciencia, proceso que estuvo acompañado por la publicación de revistas especializadas destinadas a recoger las más recientes investigaciones, los debates y todo tipo de informaciones sobre la disciplina. El propósito de este trabajo es evaluar la presencia del tema latinoamericano en la primera década de la existencia de tres publicaciones europeas particularmente importantes: el «Journal of the Anthropological Institute» de Londres, fundado en 1869; la «Revue d'Anthropologie» de Paris, fundada en 1872, y el «Zeitschrift für Ethnologie» de Berlín, también de 1872. A partir de la revisión de esos materiales se persiguen dos objetivos básicos: por un lado, aquilatar la presencia de América Latina como objeto de estudio y el interés de los científicos europeos en las temáticas de esa procedencia; por otro, definir la propia presencia, en esos medios, de la ciencia antropológica que se hacía en América Latina.

Palabras Claves: Antropología, siglo XIX, publicaciones especializadas, América Latina.

Como es bien sabido, la segunda mitad del siglo XIX fue un período seminal para la institucionalización de la Antropología como ciencia. En esos años surgieron o se afianzaron las más importantes instituciones europeas destinadas al cultivo de esta nueva disciplina, que ponía al hombre en el centro del interés. Pero además, en un contexto particularmente interesado en la creación de espacios públicos, esa expansión intelectual e institucional se produjo de la mano de un nuevo e importante fenómeno: el afán por asociar la producción del conoci-

1 Este trabajo se inscribe en el proyecto de investigación «Ingenieros Sociales. La construcción del método y el pensamiento antropológicos en Europa e Iberoamérica, siglo XIX» (BSO2001-2341), financiado por el MCyT, Madrid. 
miento a la publicación periódica de medios de prensa especializados, destinados a recoger las más recientes investigaciones, los debates por ellas suscitados y toda la información referente a los avances de la disciplina y las actuaciones de quienes la cultivaban. Medios que se dirigían, por tanto, a un vector de público con intereses específicos. Es así que a partir de 1860 y sobre todo en la década siguiente tuvo lugar una suerte de eclosión en Europa de revistas científicas dedicadas a la Antropología.

El propósito de este trabajo no es estudiar esas revistas en general, sino en relación con un ámbito geográfico específico: América Latina. Se trata, en concreto, de evaluar la presencia del tema latinoamericano en la primera década de la existencia de tres publicaciones europeas que fueron señeras en su campo: el Journal of the Anthropological Institute de Londres, fundado en 1869; la Revue d'Anthropologie de París, fundada en 1872, y el Zeitschrift für Ethnologie de Berlín, también de 1872. Cada una de estas revistas, a su vez, estaba vinculada a una Sociedad de Antropología de proyección internacional: el Royal Anthropological Institute of Great Britain and Ireland, de Londres (fundado en 1871), la Société d'Anthropologie de Paris (1869), y la Deutsche Gesellschaft für Ethnologie, Anthropologie und Urgeschchite (1869), cuya sección berlinesa se abre en el año siguiente. A partir de la revisión de esos materiales se persiguen dos objetivos básicos: por un lado, aquilatar la presencia de América Latina como objeto de estudio y el interés de los científicos europeos en las temáticas de esa procedencia; por otro, definir la propia presencia, en esos medios, de la ciencia antropológica que se hacía en América Latina.

Como punto de partida, es importante señalar que las tres revistas citadas reunían a los más importantes científicos de la época ocupados en lo que ya se llamaba desde hacía tiempo las «ciencias del hombre»², así como en ciencias afines, como la geología o la demografía. Pero en tanto medios de difusión no sólo se dirigían a los científicos reconocidos, que cumplían el doble papel de lectores y autores, sino a un público mucho más amplio de profesionales con intereses va-

2 Dada la elasticidad de una terminología que en la época estaba en pleno proceso de configuración, citaré a Benoit MASSIN, «From Virchow to Fischer. Physical Anthropology and 'Modern Race Theories' in Wilhelmine Germany». En George W. STOcKING (ed.), Volkgeist as method and ethic. Essays on boasian Ethnography and the German Anthropological Tradition. Madison, The University of Wisconsin Press, 1996, pp. 79-154. Según este autor «In the Anglo-Saxon tradition, the unmodified form 'anthropology' has, since the 1870 's, generally been used to refer to a more embracive inquiry including what in the United States have come to be called 'the four fields' -one of which is 'cultural anthropology' or (in an earlier usage) 'ehtnology'. 'Ethnology' itself has a complex history, and before its usage as an equivalent to cultural anthropology it referred (in both the Anglo-Saxon and French traditions) to 'the science of race'. In Germany (and in France as well) the term Anthropologie has (with a few exceptios) been used to refer to what in anglo-Saxon countries came to be called 'physical anthropology', whereas 'cultural anthropology' or 'ethnology' (in the more recent Anglo-Saxon sense) has been referred to by Ethnologie, Ethnographie, or Völkerkunde.» (p. 82). 
riados y sobre todo de «caballeros», personas a quienes la disposición de holgados medios económicos y tiempo libre les permitía satisfacer la curiosidad por temas científicos novedosos que estaba muy extendida en la época ${ }^{3}$. Se trataba de individuos a los que hoy quizá llamaríamos «diletantes», pero que desempeñaron un papel significativo en estas fases tempranas de institucionalización de la nueva disciplina, ya que aportaban pecuniariamente al sostenimiento de las sociedades y constituían una masa crítica receptora y consumidora de sus reuniones y publicaciones científicas. Estas últimas, a su vez, cumplieron dos misiones básicas: 1) acogieron y difundieron una parte significativa de la creación de conceptos y métodos, contribuyendo además a la delimitación de los campos de interés de las nuevas ciencias, y 2) sirvieron de plataforma para multiplicar el alcance de los debates y para crear contactos y redes entre los propios científicos.

Ese papel central en la producción y difusión del conocimiento antropológico es una de las razones que explican la selección de las tres revistas citadas para realizar este trabajo. Pero además, los tres medios elegidos cumplen un requisito importante para que pueda hacerse un análisis con voluntad comparativa: el de que haya suficiente homologación entre los términos o ámbitos que se van a comparar. En efecto, se trata de tres revistas en las que confluyen una serie de intereses. Por ejemplo, dentro de lo que fueron los grandes debates de la segunda mitad del siglo XIX, los tres medios citados respetaban la Antropología Física y estaban particularmente interesadas en dos temas: el del estudio de la división del género humano en «razas» y la cuestión de los orígenes de la humanidad. Las tres revistas se proponían, además, lograr una articulación entre las tendencias que primaban lo que los ingleses llamarían la «historia cultural del hombre», identificada con la etnografía o etnología (términos que en la época se usaban de forma más o menos intercambiable), y otra que priorizaba el estudio de las razas en sus características físicas. He dicho articulación, porque en las décadas inmediatamente anteriores se había producido un debate muy enconado entre las dos tendencias, la etnográfica y la más orientada hacia la antropología física, debate que había sido particularmente exacerbado en el ámbito británico ${ }^{4}$. Pero en la

3 Por ejemplo, de los 500 miembros de la Deutsche Gesellschaft residentes en Berlín hacia finales del siglo, 190 eran médicos, privados o académicos, 55 eran académicos no médicos, bibliotecarios o empleados de museo. Los restantes 255 incluían comerciantes, contadores, pintores, fotógrafos, funcionarios de la administración local o colonial, científicos y profesionales de distintos tipos, publicistas o libreros, sacerdotes o rabinos, viajeros y dos señoras, una de ellas novelista. Es decir, la mitad de los miembros practicaba la antropología como hobby. MASSIN [2] p. 86.

4 De hecho, el Royal Anthropological Insitute of Great Britain and Ireland surgió de la fusión de dos instituciones previas y rivales entre sí: la Ethnological Society y la Anthropological Society of London. Según George STOcKING (Victorian Anthropology, New York, the Free PressMacmillan, 1987, cap.7) la segunda era más conservadora y priorizaba los aspectos físicos y raciales de la disciplina; su modelo eran Paul Broca y la Société d'Anthropologie creada por éste en 1859, para quienes la Antropología era la ciencia global del hombre en su relación con el universo físico y las leyes que regulan su naturaleza anatómica y psicológica, es decir, todo lo relativo a su 
década a la que me estoy refiriendo - 1870-1880 — se había llegado a una suerte de voluntad de convivencia entre ambas corrientes 5 . Por otra parte, los contenidos de las tres revistas muestran que en la década seleccionada las diferencias entre poligenistas y monogenistas se estaban transformando, incluso resignificando, al quedar incluidas dentro de otro debate, el producido en torno a la aceptación o rechazo de las tesis evolucionistas en su versión darwinista. Y finalmente, algo que también pesa para que los términos de la comparación sean homologables es el hecho de que las autoridades de las tres revistas - la francesa, la alemana y la inglesa- mantenían buenas relaciones entre sí. No eran rivales, sino que desde unos intereses semejantes y un mutuo respeto, cada una de ellas actuaba desde un ámbito nacional específico, con sus propias tradiciones y controversias, y en la lengua propia del mismo. Pero lo importante a los fines de este trabajo es que esas diferencias de tradición tanto científica como idiosincrática, que creo pueden asociarse al citado término de «nacional», se van a reflejar en la recepción del tema americano. Y esto es lo que hace fructífera la comparación.

\section{AMÉRICA LATINA COMO OBJETO DE ESTUDIO}

En su conocido libro titulado Victorian Anthropology ${ }^{6}$, afirma George Stocking que hacia 1872 una serie de debates se habían cerrado, al alcanzarse consensos en tres puntos fundamentales: la gran antigüedad del hombre, su origen monogénico y el carácter progresivo del avance de la civilización. ${ }^{7}$ Sin embargo, la revisión de las grandes revistas antropológicas en la década de 1870-80 obliga al

condición de «natural». La Ethnological Society, por el contrario, era más liberal, culturalista y proclive a las ideas darwinistas. Precisamente la consolidación de estas últimas favoreció la fusión mencionada ya que la revolución darwinista, defendida principalmente por los etnólogos, vino a reforzar la visión del hombre como parte del mundo natural, contribuyendo a incorporar la etnología a un concepto más amplio de la «ciencia del hombre». De tal forma, los defensores de la etnología aceptaron formar parte de la más amplia Antropología, aunque negándose a reducir ésta a términos de antropología física en exclusividad. Sobre este tema sigue siendo particularmente útil la monografía de G. STOCKING citada en esta misma nota. Pero es importante señalar que esta visión binaria que surge fundamentalmente de los estudios sobre la tradición inglesa puede llevar a importantes deformaciones si se la extrapola a otros ámbitos. Por ejemplo, los autores que se ocupan de la antropología alemana de la misma época muestran que los mayores defensores de la antropologia física en esa país eran «liberales, individualistas, creyentes en el 'progreso' y no dudaban en negar las 'jerarquías raciales' cuando los datos empíricos las desmentían. Tal fue el caso por ejemplo de Rudol Virchow con los masai (MASsin [2] pp. 96-101).

5 Dicha convivencia volvería a romperse en el futuro, pero esto queda fuera de nuestro ámbito temporal de análisis.

6 STOCKING [4].

7 Stocking se refiere específicamente a la antropología británica de la época victoriana, pero creo que tanto su afirmación como la matización que hago en este trabajo pueden extenderse, en mayor o menor grado, al conjunto del ámbito occidental. 
menos a matizar dicha observación. Sin duda se había llegado a algunos consensos en el mainstream de la discusión científica, pero eso no era óbice para la cómoda convivencia de las propuestas más avanzadas con otras de corte más tradicional, o simplemente controvertidas, que persistían en el seno de un mismo medio e, incluso, podían introducir contradicciones dentro de un mismo artículo. No obstante, podría acordarse con Stocking en que las tres líneas de interés por él citadas asoman como una suerte de telón de fondo en una buena parte de los contenidos de las revistas seleccionadas para el análisis. En ese contexto, y como se ha anunciado en el acápite anterior, dedicaremos las páginas que siguen a aquilatar la presencia de América Latina como objeto de estudio y, también, a detectar y evaluar la propia presencia en dichos medios de la producción científica originada en el nuevo continente, ya sea por obra de latinoamericanos o de europeos residentes en esa parte del mundo.

Una primera evaluación permite constatar la indudable presencia latinoamericana en los tres medios. Pero es necesario agregar que dicha presencia no tiene la misma intensidad ni las mismas características según se trate de uno u otro medio. Asimismo, si consideramos que en esa época los puntos centrales de producción de ciencia se encontraban sobre todo en ciertos países europeos ${ }^{8}$, y si añadimos que América Latina se situaba en una especie de extrarradio con respecto a esos nodos centrales, nos encontramos con que esta región ocupaba un nicho que tenía puntos de contacto con otros ámbitos de expansión, como pueden ser Asia o Africa. Pero también había diferencias considerables de tratamiento, no sólo en relación con las demás áreas extraeuropeas sino al interior del propio espacio latinoamericano. Y esas diferencias se debían al distinto rasero con que la temática americanista, o la producción científica americana, eran percibidos por la tradición nacional desde la cual se la estaba observando, es decir, la francesa, la inglesa o la alemana.

Para facilitar el análisis, creo conveniente comenzar haciendo un breve planteamiento topográfico que nos ayude a localizar la presencia latinoamericana en las revistas antropológicas europeas. Hay que tener en cuenta que en toda revista científica existe una jerarquía de espacios. Tenemos en primer término los artículos de investigación en sí mismos. Esos artículos científicos tienen un autor, una temática y un campo de interés, y éste es el primer nivel donde hay que buscar esa presencia americana. Hay otro nivel que es la bibliografía, en concreto el anuncio de los libros de reciente aparición. Un tercer nivel, vinculado a este último, es el de las reseñas bibliográficas. Estos tres niveles existen más o menos por igual en las tres revistas. Pero hay también otros ámbitos que reciben muy distinta atención según el órgano de que se trate, lo que implica una tradición científica distinta, intereses nacionales diversos y una voluntad de proyección de alcance diferente.

8 En puridad habría que agregar la producción de los Estados Unidos, pero por razones de estrategia analítica he optado por no incluir dicho ámbito en este trabajo. También se han excluido del análisis otros enclaves europeos, como Italia y España. 
En este último sentido cabe mencionar, en primer lugar, el grado de esfuerzo que dedica una revista a la publicación, no sólo de los papers, sino de los debates que generan esos trabajos, ya que las investigaciones eran presentadas inicialmente en una reunión pública de los miembros de la sociedad y la discusión generada solía editarse junto con el paper. Desde esta perspectiva destacan sobre todo el Journal y el Zeitschrift que comparten esa interesante práctica, a diferencia de su homóloga francesa que no suele recoger los debates. Pero existe otra sección, muy importante para la vida institucional de la disciplina, que responde a títulos variados: «notas», «misceláneas» o «extractos y análisis». Es aquí donde se aprecia la voluntad de proyección extranacional de las revistas, así como el grado de interés y de respeto científico que le merecen otros ámbitos distintos al propio. Porque es en esta sección donde se informa acerca de las actividades de otras revistas o instituciones hermanas, las celebraciones de congresos o encuentros, exhibiciones temporales de interés antropológico, o bien referencias a conferencias o artículos destacados de científicos de otros países, aparecidos previamente en medios distintos al propio. $\mathrm{Y}$ en esta sección, que como he dicho es donde se ve con mayor claridad el interés y el respeto de la revista por lo que se hace en el extranjero, se detectan diferencias muy claras: el medio que más desarrolla esa sección y que más atención presta a la producción en otros ámbitos nacionales es sin duda la Revue d'Anthropologie, la sigue bastante de cerca el Zeitschrift y muy lejos queda el Journal, que pone sensiblemente menos interés en lo que sucede fuera de las fronteras del Imperio Británico, lo que se traduce en el hecho de que se le concede un espacio mucho menor.

Entrando ya en el tema central de este análisis - la presencia de América Latina en dichos medios - hay algunas temáticas que no muestran demasiadas diferencias con respecto a otros ámbitos de proyección extraeuropea, como Asia y Africa. Una de esas temáticas es el afán por explorar tierras incógnitas y entrar en contacto con grupos culturalmente ajenos. Desde esta perspectiva hay una presencia importante de informes de viajeros europeos en América Latina, que permite además apreciar la interacción informativa entre las tres revistas. Por dar un ejemplo, tiene una gran repercusión la conferencia en la que el marino británico George Chaworth Musters presenta ante el Royal Anthropological Institute de Londres algunos resultados de su estancia de un año (abril 1869-mayo1870) entre los tehuelches, la tribu patagónica cuya leyenda diera nombre a ese vasto espacio del extremo sur de América. Y creo que es significativo observar qué forma adopta esta presentación, cómo se proyecta, y, también, el entretejido de información en la que se inserta.

El 29 de mayo de 1871 — es decir, al año de su retorno a Inglaterra- Musters dicta su conferencia, que es publicada por el Journal en el volumen de 1872 bajo el título de «On the races of Patagonia». La publicación es inmediata, ya que en las tres revistas estudiadas cada tomo actúa como un anuario que recoge las actividades del año anterior. El artículo se acompaña de la transcripción de un par de intervenciones del público, lo que muestra que la presentación de Musters no 
había generado mucho debate in situ. Pero el interés internacional que despierta es superior al que logra entre sus compatriotas, porque las otras dos revistas - la francesa y la alemana - anuncian a sus lectores, en los tomos correspondientes a ese mismo año de 1872, que el trabajo de Musters ha sido publicado por el Journal. Y los anuncios no son escuetos: la nota de la Revue d'Anhropologie, por ejemplo, es de cinco páginas y está redactada por Pierre Topinard, «segundo de a bordo» de Paul Broca ${ }^{9}$. Esta fórmula se repite en el Zeitschrift ${ }^{10}$ de forma algo más breve y, en este caso, la nota está escrita nada menos que por el fundador de la propia revista, el gran Adolf Bastian. Cuando Musters publica sus informes de viaje en forma de libro (At home with the Patagonians. A year's wanderings over untrodden ground from the Straits of Magellan to the Rio Negro, Londres, 1871), éste es anunciado en la Revue d'Anthropologie y en el Zeithscrift. De la misma manera, la revista francesa informaba puntualmente a sus lectores sobre los trabajos que el antes citado médico y antropólogo alemán Adolf Bastian enviaba a la Sociedad Berlinesa desde América, continente por el que realizó un largo viaje en 1875 y $1876^{11}$. Dichos papers eran leídos públicamente en la citada institución y editados por el Zeitschrift, junto con los debates que tenían lugar después de cada lectura. De todo ello se hacía eco puntualmente la Revue d'Anthropologie, pero no la revista británica, simpre más abocada al ámbito científico desarrollado en su propia lengua. De hecho, las referencias a actividades institucionales de los franceses y alemanes eran escasas en el Journal, aunque no inexistentes. En general no hacían un seguimiento de lo publicado por las revistas homólogas, limitándose a informar sobre eventos de importancia como las exposiciones internacionales celebradas en las grandes capitales o ciertas exhibiciones que consideraban de especial interés ${ }^{12}$.

Otra presencia de América Latina en los medios europeos, principalmente el francés y el alemán, es a través de los estudios craneométricos realizados a partir de ejemplares llevados de América a Europa por los viajeros, o enviados desde el nuevo continente como una contribución a la ciencia por gente interesada en el tema, que podían ser tanto americanos como europeos allí residentes. Ejemplo de ello es la remesa de varios cráneos hecha por el cónsul alemán en Panamá. En

9 Revue d'Anthropologie, vol. I, 1872, pp. 741-745.

10 Zeitschrift für Ethnologie, vol. IV, 1872, p. 131.

11 Bastian viaja a América entre mayo de 1875 y agosto de 1876 y desde allí hace envíos periódicos de información a la Sociedad Belinesa que aparecen en diversos tomos de la revista. El más completo es el que da personalmente a su regreso a Berlín, publicado en los Vorhandlugen der Berliner Gesellschaft für Ethnologie, Anthropologie und Urgeschchite, incluidos en el volumen VIII del Zeitschrift für Ethnologie, 1876. Hay un viaje anterior realizado por Bastian en 1869, cuyos resultados se recogen en sus Baiträge zur Ethnologie, publicados en cuatro entregas a partir de 1870. En ellos hace mútiples referencias a temáticas sudamericanas.

12 Tal fue el caso, por ejemplo, del anuncio hecho por Rudolf Virchow sobre una muestra temporal de simios en los Jardines del Acuario de Berlín (Journal of the Anthropological Institute, vol. VI, 1877). 
Berlín son estudiados personalmente por el fundador de la Berliner Gesellschaft für Ethnologie, Anthropologie und Urgeschchite, Rudolf Virchow, quien presenta los resultados de dicho análisis en una sesión de la Sociedad, que son publicados más tarde en el Zeitschrift junto con el debate a que han dado lugar ${ }^{13}$. Este tipo de envíos también despierta interés en Francia, aunque allí es menos usual encontrar análisis puntuales. En este caso los materiales americanos suelen incluirse en trabajos más amplios, como los del ya citado Pierre Topinard, mano derecha de Paul Broca y su heredero en la Société d'Anthropologie.

Si los estudios craneométricos se insertaban en las más modernas preocupaciones antropológicas, la presencia americana se detecta también en investigaciones más vinculadas con intereses de larga tradición. Me refiero a la perspectiva del estudio de las «antigüedades», que se verifica de dos maneras. Por un lado, en la forma de artículos sobre la arqueología y la prehistoria de una región específica, como los numerosos papers sobre las antigüedades peruanas publicados por T.J. Hutchinson en el Journal ${ }^{14}$; y, por otra parte, en forma de referencias puntuales a ejemplos o casos americanos dentro de trabajos más globales sobre mitologías comparadas, culturas comparadas o prácticas rituales, como enterramientos o métodos de navegación. Con este tipo de enfoque comparativo, por ejemplo, son típicos los trabajos de Lane Fox Pitt Rivers y Hyde Clarke ${ }^{15}$ publicados por el Journal. Junto a estos artículos que aún hoy consideraríamos «científicos», se aprecia todavía una presencia muy notable de trabajos que insisten en vincular las altas culturas americanas a unos supuestos orígenes en las civilizaciones del Viejo Mundo, sean egipcios, arios, atlántidos, etc. Lo cierto es que para la década que nos ocupa esta última perspectiva se estaba quedando anticuada y perdía prestigio rápidamente, pero sin embargo seguiría encontrando cultores hasta ya entrado el siglo veinte ${ }^{16}$.

Ahora bien, habría que preguntarse si en términos comparativos este tipo de referencias implican una amplia presencia de América Latina en las revistas an-

13 Zeitschrift für Ethnologie, vol. IV, 1872, pp. 22 y ss de los Vorhandlungen. Es sólo uno de tantos ejemplos posibles, ya que los análisis de Virchow sobre cráneos enviados desde América Central y del Sur aparecen publicados de forma recurrente a lo largo de toda la década.

14 T.J. Hutchinson, «Ancient Peruvian Skulls», Journal of the Anthropological Institute, vol. III, 1874, pp. 86 y ss; «Explorations amongst ancient burial grounds of Peru», III, 1874, pp. 311 y ss. (en el debate de este paper aparece un «Sr. González» que se dirige a la audiencia en francés); continuación del mismo paper en IV, 1875, pp. 2 y ss; "Anthropology of Prehistoric Peru», IV, 1875 , pp. 438 y ss.

15 Por ejemplo Lane Fox: «Early modes of navigation», IV, 1875, pp. 399 y ss.; Hyde Clarke: «On Serpent and Siva Worship and Mythology in Central America, Africa and Asia», VI, 1876, pp. 247 y ss.

16 Las referencias a los orígenes «atlántidos» de diversas culturas de occidente son recurrentes en varios trabajos aparecidos en las tres revistas a lo largo de la década. Con respecto a la atribución de diversos orígenes a las culturas americanas (atlántido, chino, japonés, vasco, etc.), es sorprendente el alto número de artículos que puede encontrarse con sólo revisar las actas de los Congresos de Americanistas, en particular el primero de ellos, que tuvo lugar en Nancy en 1872. 
tropológicas europeas. Lo cierto es que en porcentaje de espacio ocupado, dicha presencia es bastante relativa. En un volumen cualquiera de una de las revistas, que suelen incluir entre cinco y siete artículos, puede haber uno referido a América, o quizás ninguno. Más significativa es su presencia en las listas bibliográficas donde las referencias son abundantes en términos absolutos ${ }^{17}$, pero escasas si se las compara con los títulos publicados sobre cuestiones vinculadas a Africa, Asia o la propia Europa. Esta proporción se repite en las secciones dedicadas a reseñas o a acontecimientos vinculados a la disciplina.

No obstante, si consideramos esta cuestión en perspectiva no cuantitativa sino cualitativa, nos encontramos con una situación muy interesante: en la década de los setenta empieza a haber presencia de trabajos científicos hechos en América Latina, en muchos casos por residentes europeos en el nuevo continente, pero también por los propios americanos.

En mi opinión, aquí es pertinente contrastar la hipótesis de Jesús Bustamante defendida en este mismo volumen ${ }^{18}$, sobre las motivaciones de esa nueva ciencia del hombre que era la Antropología. Hipótesis que responde a la interrogante de si se trató de una ciencia cuyo origen estuvo vinculado de forma prioritaria a situaciones y contactos generados por la expansión colonial o, sobre todo, al objetivo del conocimiento de las propias poblaciones. La primera hipótesis, la de la expansión colonial, ha sido muy defendida en los ámbitos anglosajones. Caso paradigmático es el de George Stocking, según el cual el surgimiento de la antropología como ciencia no puede separarse de la expansión imperial y del «autoasumido poder y obligación de tutelar a las poblaciones incivilizadas de piel oscura» ${ }^{19}$. Bustamante, en cambio, propone que los orígenes de la Antropología se vinculan al interés por el conocimiento científico de las propias poblaciones.

Lo cierto es que la revisión de las tres grandes revistas antropológicas europeas en la década citada muestra una presencia muy grande de dos temas no únicos, pero sí prioritarios: el problema de la constitución física de las poblaciones europeas y su distribución en el espacio, analizados por científicos originales de la misma población estudiada, y la cuestión de los orígenes de la humanidad, motivada este última por los descubrimientos que se estaban haciendo en la propia Europa $^{20}$. En ambos casos asoman los interrogantes de los propios antropólo-

17 El interés bibliográfico supera la perspectiva exclusivamente antropológica o etnológica, ya que la información abarca títulos sobre temas históricos, jurídicos, geográficos, estadísticos, etc.

18 Véase su artículo titulado «La conformación de la Antropología como disciplina cinetífica, el Museo Nacional de México y los Congresos Internacionales de Americanistas». Asimismo la conferencia del mismo autor sobre «Una reflexión sobre los orígenes y razón de la Antropología: ¿acción colonial o acción sobre la propia sociedad?» dictada en el Museo Etnolográfico de Buenos Aires, 11 julio de 2003.

19 STOcKing [4], p. .3.

20 Para un excelente panorama histórico sobre este último tema véase el texto de Bowdoin VAN RIPER: Men among Mammoths. Victorian Science and the discovery of Human Prehistory. Chicago and London, The University of Chicago Press, 1993. 
gos sobre sí mismos, en tanto miembros de la especie humana. Éste parece ser precisamente el marco fundamental de la mayoría de los trabajos referidos a las llamadas razas primitivas o razas inferiores que habitaban los ámbitos geográficos de la expansión colonial. Es decir, hay una preeminencia de la perspectiva comparativa, motivada por el afán de estudiar cómo eran esos grupos humanos - tanto en la antigüedad de sus restos físicos como en sus costumbres todavía vivas - que se mantenían como formas fósiles de estadios culturales y físicos muy antiguos, con el objetivo último de que echaran luz sobre los primeros ancestros del hombre europeo contemporáneo. Creo que esto refuerza la tesis antes citada, y proporciona un contexto de comprensión para el análisis de la perspectiva americana que presentaremos a continuación.

\section{AMÉRICA LATINA COMO ÁMBITO PRODUCTOR DE CONOCIMIENTO ANTROPOLÓGICO}

Posiblemente fue esta condición de la Antropología como ciencia que se ocupa principalmente de las propias poblaciones lo que atrajo la atención hacia la nueva disciplina de estudiosos no europeos, en un grado sobre el que todavía hay un desconocimiento casi total. No obstante es posible detectar algunas referencias, no por puntuales menos significativas. Algún ejemplo de ello puede encontrase en relación con la labor pedagógica de Paul Broca ${ }^{21}$. Como es bien sabido, el famoso médico y antropólogo francés fundó en 1859 la Societé d'Anthropologie y, en 1872, la Revue d'Anthropologie. Esta intensa labor se completó con la organización temprana de un Laboratorio en el que se realizaban investigaciones y se impartía docencia sobre Antropología Física que condujo finalmente a la organización de la Ecole d'Anthropologie, cuyos cursos comenzaron en 1876. El currículo de esta última muestra una enseñanza con un fuerte acento en la Antropología Física, pero que también incluía materias centradas en la Etnografía, la Lingüística y la Demografía.

No existen trabajos - que yo conozca al menos- sobre los estudiantes que acudían a los cursos dictados tanto en el Laboratorio como en la Escuela de Antropología. No obstante pueden encontrarse algunas interesantes referencias en publicaciones de la época, como la propia Revue d'Anthropologie. Una nota publicada en 1878, por ejemplo, señalaba la presencia de «razas exóticas en París» ${ }^{22}$. La terminología utilizada hace pensar inicialmente en esa práctica, bastante desarrollada en la segunda mitad del siglo XIX, de trasladar a Europa contingentes de los llamados «grupos primitivos» para ser expuestos en las exposiciones universales ${ }^{23}$.

21 Sobre Paul Broca véase el imprescindible Préface de Claude BlancKaERT a la edición de Paul Broca: Mémoires d'Anthropologie. Paris, Jean Michel Place, 1989 (pp. i-xliii).

22 Revue d'Anthropologie, Vol. VII, p. 181.

23 Sobre la exhibición de grupos «exóticos» en Europa existe una nutrida bibliografía. Véase, entre otros, Nicolás BANCEL, Pascal Blanchard, Gilles Bö̈TSCH, Éric Deroo et Sandrine LeMAI- 
Pero una lectura más atenta desvela que en el caso citado el autor de la nota no se estaba refiriendo a las «razas exóticas» expuestas en el Jardín de Aclimatación, sino a los estudiantes de países extraeuropeos que acudían a París con el propósito de asistir a los cursos de la Escuela de Antropología. El término «razas exóticas» estaba, claro está, usado de forma irónica. Y la revista nombraba en particular a estudiantes japoneses, peruanos y brasileños; pero también —agregaba - a negros «de pelo lanudo» (au poil lanu).

De lo anterior podría inferirse que precisamente por ser una ciencia que tenía como interés prioritario a las propias poblaciones, la Antropología había comenzado a atraer a estudiosos de áreas no centrales que deseaban analizar a sus propias poblaciones en tanto tales, es decir, no como objetos curiosos sino como una realidad sociológica de la que ellos mismos formaban parte. Y no es casual que esos aspirantes a antropólogos mostrasen - como se afirma en la Revue d'Anthropologie - particular interés en los cuestionarios elaborados por las sociedades para guía de sus propios científicos.

Ahora bien, la presencia en Europa de personas de otros continentes que buscaban formarse en los métodos de las nuevas y fascinantes ciencias del hombre no implica que cualquier estudioso proveniente de áreas no centrales encontrara abiertas las páginas de las revistas europeas de Antropología, especialmente en ese primer escalón de la jerarquía de espacios que hemos identificado con la publicación de investigaciones originales. Alcanzar este nivel implicaba haber obtenido un grado de reconocimiento que sólo se produjo en casos contados. En la década que nos ocupa he identificado muy pocos de esos casos y todos ellos, precisamente, coinciden con trabajos científicos originados en América Latina ${ }^{24}$. Pero tales trabajos no recibieron el mismo tratamiento ni la misma capacidad de proyección según se tratase de una u otra revista.

En el Journal of the Anthropological Institute, por ejemplo, los artículos y notas de temática latinoamericana suelen corresponder a firmas de autores euro-

RE (eds), Zoos humains XIXe et XXe siècles (de la Vénus hottentote aux «reality shows»), París, Éditions La Découverte, 2002; Burton BENEDICT, «Rituals of representation: Ethnic stereotypes and colonized peoples at World's Fairs», en R. RYDELL and N. GwINN (eds), Fair Representations, VU University Press, Amsterdam, 1994; Raymond CORBEY, «Ethnographic Showcases, 1870-1930», Cultural Anthropology 8 (3), 1993, pp. 338-369; Isabelle GALA, Des sauvages au jardin. Les exhibitions etnographiques du jardin zoologique d'acclimatation de 1887 à 1912, Tapuscrit [document ronéoté], s.1., s.d., 135 pp [Musée des arts et traditions populaires: $2^{\circ}$ A 3.61 60]; Paul GreEnhalgh, Ephemeral vistas. The «Expositions Universelles», Great Exhibitions and World's Fairs, 1851-1939, Manchester, Manchester University Press, 1988; Bernd LINDFORs (ed), Africans on Stage. Studies in Ethnological Show Business. Bloomington \& Indianapolis/ Cape Town Indiana University Press/ David Philip, 1999; Luis Ángel SÁNCHEZ GómEZ, Un Imperio en la vitrina. El colonialismo español en el Pacífico y la exposición de Filipinas de 1887, Madrid, CSIC, Colección Tierra Nueva e Cielo Nuevo, 2003.

24 Insisto en que no estoy tomando en cuenta la producción científica originada en los Estados Unidos. 
peos o norteamericanos. Con alguna rara excepción. Por ejemplo, en 1873 el famoso explorador y lingüista Richard Burton tradujo y presentó una memoria sobre los habitantes primitivos de Minas Gerais, enviada por el brasileño M. Henríquez Gerber $^{25}$ que, por cierto, fue largamente reseñada en la Revue d'Anthropologie. Pero lo que se deduce en términos generales es que el Royal Anthropological Institute of Great Britain and Ireland de Londres no mantenía relaciones activas con grupos de ámbitos afines latinoamericanos. Por el contrario, el panorama cambia cuando se revisan las otras dos revistas.

En el Zeitschrift für Ethnologie es notable la presencia de trabajos enviados por europeos que residían de forma permanente en América del Sur. Además de nombres dispersos que asoman de forma esporádica, surgen tres personajes cuya presencia destacada demuestra la existencia de sólidos lazos científicos con la Sociedad Berlinesa. Adolf Ernst, profesor de Ciencias Naturales en Hamburgo, que marchó a Caracas en 1861 por encargo del gobierno alemán; Rudolf Armand Philippi, también alemán a pesar de su apellido, que en 1851 se trasladó a Santiago de Chile, y un tercer personaje muy conocido en América del Sur: Hermann Burmeister, profesor de Halle que en 1861 se estableció en Buenos Aires. Los tres eran alemanes, médicos y naturalistas, los tres ejercieron la docencia primero en Alemania y después en sus países de adopción, los tres murieron allí, y, lo que es muy significativo, los tres fueron Directores de Museos dedicados a la Historia Natural en los respectivos países de América del Sur en que se instalaron. En el caso de Ernst, además, fue fundador del Museo de Caracas.

¿Cómo figuran estos personajes en el Zeitschrift? En primer lugar hay que señalar que todos ellos son miembros correspondientes de la Sociedad Berlinesa de Antropología, lista de honor en la que comparten sitio con algunos de los más importantes antropólogos de la época. Segundo, en la sección bibliográfica de la revista aparecen anunciadas sus publicaciones y, en algunos casos, hay reseñas de las mismas. Y finalmente entran también en el ámbito de mayor jerarquía, que es el de los papers presentados en las sesiones públicas de la Sociedad, que luego son publicados, junto con el debate, en el Zeitschrift ${ }^{26}$. En el caso de Burmeister,

25 Journal of the Anthropological Institute, II, 1873, pp. 407y ss.

26 Adolf Ernst (miembro correspondiente desde 1878): sobre los indios Guajiros del sur de Caracas (mediciones) (II, 1870, pp. 328y ss.); sobre la población de Venezuela (IV, 1872, pp. 22y ss.). Rudolf A.Philippi (miembro correspondiente en 1872): sobre un cráneo chileno que además ha mandado para la colección de la S.Berlinesa (IV, 1872, pp. 195y ss.); sobre los instrumentos de madera, piedra y metal de los araucanos (V, 1873, pp. 101y ss.); sobre los Indios Cunco y la alfarería de Chile (VI, 1874, pp. 178y ss.); sobre objetos encontrados en tumbas de indios Cunco (VII, 1875, pp. 81y ss.); sobre los jeroglíficos de la isla de Pascua (VIII, 1876, pp. 37y ss.); nota sobre recepción de objetos enviados desde Buenos Aires por Andrés Lamas (XI, 1879, pp. 85y ss.). Hermann Burmeister (miembro correspondiente en 1871): sobre antigüedades en el Río Negro y el Río Paraná (IV, 1872, pp. 196 y ss,); sobre las antigüedades de los Estados del Plata. Analiza 4 cráneos de indios del tiempo anterior a la conquista (de la colección de Francisco Moreno) (V, 1873, pp. 171y ss.); sobre los antiguos habitantes del Plata (es continuación del anterior) (VII, 1875, pp. 58y ss.). 
además, tiene algún valor agregado, como es el hecho de que el gran Rudolf Virchow mantenga un debate público con él sobre cuestiones de mediciones (en concreto, sobre si la medida de 6 veces y media de un pie es la longitud de la recta de la altura del hombre), que es publicado por la revista ${ }^{27}$.

Pero hay más: el segundo artículo de Burmeister enviado desde Buenos Aires y publicado en el Zeitschrift de 1873 es un estudio titulado «Las antigüedades de los Estados del Plata». En él analiza «cuatro cráneos de indios del tiempo anterior a la conquista» ${ }^{28}$ y agrega que dichos cráneos forman parte de la rica colección de un amigo suyo, quien ha enviado una parte de ella a la Sociedad Berlinesa. Se trata — añade Burmeister - de «el único hombre de aquí que con auténtica seriedad científica se está dedicando al estudio de la antropología y la paleontología». Anuncia además el viaje de este amigo suyo a la Patagonia. El «amigo» citado de manera tan entusiasta por Burmeister es Francisco Moreno, bonaerense muy conocido como explorador de la Patagonia, como director del Museo de Ciencias Naturales de Buenos Aires - cargo en el que sucede al propio Burmeister-y, sobre todo, como fundador y primer director del Museo de Ciencias Naturales de La Plata ${ }^{29}$.

En el año siguiente - 1874- Virchow redacta un informe sobre los citados cráneos estudiados por Burmeister, haciendo referencia explícita a los materiales que Francisco Moreno había presentado personalmente en París y que fueran comentados por Paul Broca en la Revue d'Anthropologie ese mismo año de 1874. En este punto hay dos temas que interesa destacar. Por un lado, Virchow hace un elogio de la iniciativa de Moreno al reunir cráneos antiguos y enviarlos para su estudio, mostrándolo como un ejemplo que debiera ser seguido por científicos de América y otras partes del mundo. Este comentario resulta ser la señal de partida para que le empiecen a «llover» cráneos enviados desde América por individuos interesados en el tema, algunos de ellos reconocidos en los círculos científicos o intelectuales — como Andrés Lamas de Argentina, José Melgar y Serrano de

27 Zeitschrift für Ethnologie, vol. VII, 1875, pp. 159 y ss.

28 Cfr. nota anterior.

29 Sobre Francisco Moreno cfr. Mónica QuIJADA, «Ancestros, ciudadanos, piezas de museo. Francisco P. Moreno y la articulación del indígena en la construcción nacional argentina (siglo XIX)», Estudios Interdisciplinarios de América Latina y el Caribe (Tel Aviv), vol. 9 núm. 2, juliodiciembre, 1998, pp. 21-46. Sobre los orígenes de la Antropología en Argentina y el aporte de los científicos de habla alemana, cfr. Patricia Arenas, Antropología en la Argentina. El aporte de los cientificos de habla alemana, Buenos Aires, Institución Cultural Argentino-Germana, Museo Etnográfico «J.B. Ambrosetti», Facultad de Filosofía y Letras de la UBA, 1991; Sociedad Científica Argentina, Evolución de las Ciencias en la República Argentina 1872-1972. Tomo X: Antropología, Centro Argentino de Etnología Americana (CONACYT), Sociedad Científica Argentina, [Buenos Aires], 1985; Susana GARCíA e Irina PODGORNY, «El sabio tiene una patria. La Gran Guera y la comunidad científica argentina», Ciencia Hoy, 10/55, 1999, pp. 24-34. Sobre el Museo de La Plata cfr. Irina PoDGORNY, «De razón a Facultad: funciones del Museo de La Plata en el período 1890-1920», Runa, 22, 1995, pp. 89-104; Idem, El argentino despertar de las faunas y de las gentes prehistóricas: coleccionistas, museos y estudiosos en la Argentina entre 1880 y 1910, Buenos Aires, Eudeba, 2000. 
México, el propio Philippi desde Santiago de Chile e incluso Don Pedro de Alcántara, Emperador del Brasil-, y otros menos - como varios cónsules de Alemania y Francia que prestan servicio en distintos países del continente.

Pero hay una segunda cuestión aún más significativa: Francisco Moreno no sólo enviaba cráneos, sino que en el citado año de 1874 publica un artículo completo en la Revue d'Anthropologie, titulado «Descripción de cementerios y Paraderos antiguos de la Patagonia ${ }^{30}$. Este artículo, a su vez, aparece en las referencias bibliográficas del Zeitschrift el año siguiente, 1875. En 1878 hacen a Moreno socio correspondiente de la Sociedad Berlinesa de Etnografía, Antropología e Historia Antigua (por cierto, sólo un año después de concedérsele el mismo honor a Paul Broca y Charles Darwin). Y empiezan a cruzarse las referencias. Por ejemplo, en $1878^{31}$ el Zeitschrift anuncia dos reseñas del libro de Moreno sobre sus exploraciones a la Patagonia, aparecidas ambas en el Geographical Magazine de Londres ${ }^{32}$.

El citado artículo de Moreno, aparecido en la Revue d'Anhropologie, no sólo es el primer estudio de un latinoamericano editado por una de las grandes revistas europeas especializadas, sino que funciona como una especie de señal de partida para la publicación por la revista de Paul Broca, en los años sucesivos, de un número quizá no muy grande pero sí significativo de artículos enviados desde Argentina por gente nacional de ese país. En 1878 aparecen un artículo de Estanislao Zeballos sobre «Un túmulo prehistórico en Buenos Aires»" 33 y otro de Ramón Lista sobre «Paraderos en la provincia de Entre Ríos $»^{34}$. En el volumen corresponiente al año siguiente, 1879, se publica el extenso y muy conocido artículo de Florentino Ameghino sobre el Hombre Prehistórico en el Plata ${ }^{35}$. El volumen correspondiente a 1880 se abre con un segundo trabajo del propio Ameghino, complementario del anterior, que lleva por título «Armas e instrumentos del hombre prehistórico de las pampas ${ }^{36}$. A su vez, desde 1874 el Zeitschrift für Ehtnologie comienza a publicar trabajos de muy diversa extensión enviados desde América Latina. El más significativo es un estudio sobre tribus indígenas del territorio de San Martín (Colombia), remitido dese Bogotá por Nicolás Sáenz ${ }^{37}$. Es interesante constatar que el Zeitschrift publica este trabajo simultáneamente en alemán y español por expreso deseo

30 Revue d'Anthropologie, Vol. III, 1874, pp. 72y ss.

31 Zeitschrift für Ethnologie, Vol. X, p. 303.

32 Geographical Magazine, vol. IV, 1877, p. 209 y vol. V, 1878, p. 209.

33 Revue d'Anhropologie, vol. VII, 1878, pp. 537 y ss.

34 Revue d'Anhropologie, vol. VII, 1878, pp. 365 y ss.

35 Revue d'Anhropologie, vol. III, 1879, pp. 211 y ss. Sobre las redes de científicos argentinos y franceses en el ámbito de las colecciones paleontológicas véase Irina PODGORNY, «Los gliptodontes en París: las colecciones de mamíferos fósiles pampeanos en los museos europeos del siglo XIX», en Marcelo MONSERRAT (comp.), La ciencia en la Argentina entre siglos. Textos, contextos e instituciones, Buenos Aires, 2000, pp. 308-327.

36 Revue d'Anhropologie, vol. IX, 1880, pp. 1 y ss.

37 Zeitschrift für Ehtnologie, vol. VIII, 1876, pp. 327 y ss. 
del autor, quien así lo solicita con el objetivo de que «pueda circular también entre sus compatriotas»; aunque importa señalar que este caso de publicación bilingüe es excepcional, posiblemente por no haberse producido otras solicitudes en el mismo sentido ${ }^{38}$.

Todo lo anterior produce a su vez un segundo nivel de presencia: las citas. Por supuesto que nada hay que pueda compararse a los debates que generan las tesis de Morgan o los propios trabajos craneométricos de Samuel Morton. Pero lo cierto es que empieza a haber referencias cada vez más frecuentes a las aportaciones de Francisco Moreno, sea su trabajo sobre los Paraderos, sus publicaciones sobre viajes a la Patagonia, o los antiguos cráneos de esa misma procedencia que aporta a la Société de Paris. Y también empieza a citarse a Florentino Ameghino. Burmeister, por su parte, suele estar muy presente en los trabajos de los alemanes. Pero además de esta presencia creciente, que alcanza un nivel importante a final de la década de 1870-80, hay una cuestión significativa que es importante señalar.

No se trata sólo de que estos estudiosos procedentes de América Latina hayan logrado publicar en revistas tan prestigiosas como la Revue d'Anthropologie o el Zeitschrift für Ethnologie, sino que no lo hacen desde cualquier temática o enfoque. No publican trabajos, por ejemplo, donde intenten demostrar los orígenes egipcios de los mapuches, sino que se incorporan en la cresta de la ola, en los debates más punteros del momento, en particular el problema del origen de la humanidad a través del hallazgo de restos fósiles humanos y su datación mediante la paleontología. Y lo cierto es que en la década que nos ocupa los dos países latinoamericanos que alimentaban con sus hallazgos y propuestas las tendencias científicas más modernas eran Argentina y Brasil, desde dos perspectivas fundamentales. Por un lado, el descubrimiento de antiguos restos fósiles, tanto humanos como de animales extinguidos, en un momento en que los ámbitos científicos estaban abocados a la renovación de los sistemas de datación geológica y a los debates sobre la profundidad del tiempo. Por otro, la vinculación de los cráneos y materiales óseos con razas primitivas actuales, como era el caso de las tribus vivientes de botocudos y jíbaros que los paleoantropólogos asociaban a los fósiles de Lagoa Santa en Brasil, o las vinculaciones establecidas entre los antiguos cráneos descubiertos por Moreno, y los grupos de araucanos, tehuelches y fueguinos que aún habitaban la Patagonia y la Tierra del Fuego. En ese ejercicio de articulación de los grupos «primitivos» contemporáneos y la elaboración de teorías sobre los supuestos orígenes de la humanidad, los indígenas sudamericanos y sus ancestros fósiles rivalizaban con otro grupo, de mundo no sólo «nuevo» sino «novísimo»: los aborígenes australianos.

De hecho, lo que estaban haciendo gente como Moreno, Ameghino, Zevallos y otros era integrar los materiales fósiles sudamericanos en el mismo nivel de

38 Hay otros trabajos también enviados por latinoamericanos, pero son pocos, breves y muy puntuales: un corto artículo sobre antigüedades en Bogotá, de Rafael Zerda (vol. VI, 1874, pp. 160y ss.) y una carta de José Melgar y Serrano en la que se refiere a antigüedades mexicanas (vol. VI, 1874, p. 77). 
análisis que los neanderthales y los cromagnones. De esa forma incorporaban sus territorios patrios al mainstream de la discusión científica, lo que se reflejaba en el hecho de haber logrado ocupar el primer escalón en la jerarquía de espacios de las más prestigiosas revistas antropológicas europeas.

Ahora bien, esta integración de los trabajos citados en los debates más avanzados de la época sobre el origen del hombre y en el primer nivel de sus órganos de difusión, contribuye también a explicar el hecho de que sea el ámbito francés el más proclive a recoger no sólo los materiales, sino las elaboraciones y tesis propuestas por los sudamericanos. En efecto, en la década de 1870 y particularmente en su segunda mitad, los estudios de esta temática constituían uno de los debates fundamentales recogidos por la revista francesa, abocados como estaban a él plumas de primera línea como Quatrefages, Topinard, Hovelacque, Hamy y el propio Broca $^{39}$. Y no está de más recordar que este último eligió la problemática de «Las razas fósiles de la Europea Occidental» como tema de la conferencia de apertura de la novena sesión de las Sociedad Francesa para el Avance de las Ciencias, en 1879. Fueron precisamente Broca y el grupo de antropólogos a él vinculado los que más favorecieron las propuestas de Ameghino y de Moreno en favor del autoctonismo del hombre prehistórico sudamericano e, incluso, la posibilidad de que el origen de la humanidad se hallara en la Patagonia ${ }^{40}$. Agreguemos a ello que Francisco Moreno fue alumno distinguido de Broca en la École d'Antropologie (1878-79), donde fue acogido por el maestro, en su cátedra y en su casa, como un par debido a sus méritos personales, científicos e institucionales; entre ellos, el hecho de que en el período de su estancia en París Francisco Moreno era ya Director del Museo de Ciencias Naturales de Buenos Aires. A diferencia de los franceses, los alemanes tenían menos interés en el debate sobre los orígenes de la humanidad y el propio Virchow fue uno de los científicos que defendió la afirmación de que los cráneos neanderthales no eran otra cosa que fósiles con deformaciones de orden patológi$\mathrm{co}^{41}$. En 1877 todavía hablaba en términos de «la existencia del hombre durante el período diluvial en el norte de Alemania». Esto explica la gran recepción que dio el Zeitschrift a trabajos de Burmeister, quien hasta fechas muy avanzadas seguía utilizando ese tipo de categorías, y el hecho de que tuvieran acogida inmediata y entusiasta los materiales enviados por Moreno, pero no así sus elaboraciones.

39 No debe olvidarse que uno de los más grandes descubridores de la antigüedad del hombre en Europa fue el francés Boucher de Perthes. Por otra parte, la Société d'Anthropologie consideraba la problemática del origen del hombre y los testimonios prehistóricos de la cultura, junto con el estudio de las razas humanas, como los tres ejes fundamentales de su labor investigadora.

40 Sobre las propuestas de Francisco Moreno véase QuIJADA [30]. Sobre Florentino Ameghino algunos de los planteamientos más recientes se deben a PODGORNY, en particular sus trabajos citados en [29]. Véase también, de la misma autora, «De la santidad laica del científico: Florentino Ameghino y el espectáculo de la ciencia en la Argentina moderna», Entrepasados, Revista de Historia, 13, 2001, pp. 37-61.

41 Zeitschrift für Ethnologie, 1872. 
Por el contrario, el presidente de la Sociedad Berlinesa priorizó los estudios antropométricos sobre fósiles o individuos vivos, y en este sentido la presencia de América Latina en el Zeitschrift supera a su homóloga parisina. Los numerosos casos rastreables en la revista berlinesa comprenden desde observaciones in situ enviadas por europeos residentes en Sudamérica, como Ernst y Philippire, hasta los análisis antropométricos realizados sobre individuos trasladados a Europa para las exposiciones universales; caso este último en que son particularmente significativos los estudios que hace Virchow sobre araucanos y esquimales trasladados a Berlín ${ }^{43}$.

De tal forma, a través tanto de materiales físicos como de elaboraciones vinculadas a «los más antiguos representantes del hombre sobre la tierra», los sudamericanos lograron integrarse al mainstream del debate antropológico, llegando a ocupar todas los niveles topográficos de las principales revistas europeas. Y es importante insistir en que se trataba de espacios jerarquizados, a partir de los cuales se organizaban los intereses científicos y la voluntad de proyección nacional e internacional de los círculos intelectuales cuya portavocía ejercían. Por ello, aunque en esta década temprana la presencia de América Latina en esos medios no sea particularmente amplia si se la compara con los materiales referidos a otras áreas extraeuropeas, así como a la propia Europa, lo cierto es que dicha presencia se vuelve significativa desde una perspectiva cualitativa, que tiene en cuenta la importancia de los espacios ocupados, el interés que despiertan los incipientes campos de desarrollo de la nueva ciencia en esa parte del mundo occidental, y el prestigio que van ganando los científicos que desde allí se incorporan al debate internacional.

The institutionalization of Anthropology as a science was achieved in the second half of the $19^{\text {th }}$ Century. This process was accompanied by the appearance of specialized media destined to the publication of research papers, debates, and all type of disciplinary information. The purpose of this article is to evaluate the presence of Latin America in three particularly influential European reviews in the first decade of their existence: the "Journal of the Anthropological Institute» (London, founded in 1869); the "Revue d'Anthropologie» (Paris, founded in 1872), and the "Zeitschrift für Ethnologie» (Berlin, founded in 1872). It is aimed to evaluate 1) the presence of Latin America as an object of study, and the interest of European anthropologists in Latin American topics; and 2) the presence in those reviews of anthropological research carried out by Latin American nationals or scholars currently residing there.

KeY WORDS: Anthropology, $19^{\text {th }}$ Century, specialized reviews, Latin America.

42 Véase nota 26 supra.

43 Rudolf VIRCHOW, «Drei Patagonier», Zeitschrift für Ethnologie, vol. XI, 1879, pp. 198 y ss. Informe del mismo autor sobre esquimales llevados a Berlín, vol. XII, 1880, pp. 274 y ss. 